\title{
La domestication des plantes en Océanie et les contraintes de la voie asexuée
}

Vincent Lebot

\section{(2) OpenEdition \\ 1 Journals}

\section{Édition électronique}

URL : http://journals.openedition.org/jso/1382

DOI : $10.4000 /$ jso. 1382

ISSN : 1760-7256

\section{Éditeur}

Société des océanistes

\section{Édition imprimée}

Date de publication : 1 décembre 2002

Pagination : 45-61

ISSN : 0300-953x

\section{Référence électronique}

Vincent Lebot, «La domestication des plantes en Océanie et les contraintes de la voie asexuée », Journal de la Société des Océanistes [En ligne], 114-115 | Année 2002, mis en ligne le 26 mai 2008, consulté le 22 mars 2021. URL : http://journals.openedition.org/jso/1382 ; DOI : https://doi.org/ $10.4000 /$ jso. 1382

\section{(c) (i) $\ominus$}

Journal de la société des océanistes est mis à disposition selon les termes de la Licence Creative Commons Attribution - Pas d'Utilisation Commerciale - Pas de Modification 4.0 International. 


\title{
La domestication des plantes en Océanie et les contraintes de la voie asexuée
}

\author{
par
}

\author{
Vincent LEBOT *
}

\section{RÉSUMÉ}

À l'exception du cocotier, les cultures traditionnelles d'Océanie (arbre à pain, bananiers, canne à sucre, ignames, kava et taros) sont à multiplication végétative exclusive et les insulaires n'utilisent jamais de graines pour les cultiver ou les distribuer. Ces clones ont été déplacés sur de très grandes distances géographiques au gré des migrations humaines et des échanges de matériel végétal. Les apports récents des nouveaux outils de la biologie moléculaire contribuent à élucider de nombreuses énigmes d'ethnobotanique océanienne. Ces deux dernières décennies ont en effet permis de conduire des inventaires de ressources génétiques des principales plantes cultivées dans le Pacifique. Les études de diversité qui ont été réalisées à l'aide de marqueurs moléculaires, sur plusieurs milliers de cultivars, permettent d'utiliser les empreintes génétiques pour clarifier les généalogies et révéler les processus de domestication. Il apparaît que les nombreux cultivars qu'utilisent les horticulteurs océaniens trouvent leur origine géographique sur la plaque continentale Sahul et non pas en Asie comme supposé antérieurement. Dans certains cas, la domestication a toujours cours. Nous présentons une synthèse des connaissances acquises sur l'origine de ces plantes et tentons d'expliquer les fortes contraintes que rencontrent aujourd'hui les horticulteurs qui manipulent ces cultivars stériles. La vulnérabilité génétique des espèces cultivées est accentuée par les rapides changements environnementaux.

MOTS -CLÉS : domestication, changements environnementaux, vulnérabilité génétique.

\begin{abstract}
Except for the coconut all the traditional crops of the Pacific are propagated asexually and farmers never use seeds to cultivate them. Exchanges of planting material and human migrations have distributed these clones across very long distances. The recent advances made by molecular biology are valuable contributions to elucidate the long standing enigmas of ethnobotany regarding the geographic origin of these plants. During the last two decades, several ecogeographical surveys of the genetic resources have been conducted for the major crops (breadfruit, bananas, sugarcane, yams, taros and kava) and have produced significant results. Genetic diversity studies conducted with molecular markers on several thousands of cultivars clarify their phylogeny and provide insights on domestication processes. It appears that these traditional crops found their geographic origin on the Sahul plate itself rather than being introduced from the Asian Sunda plate. In some cases, domestication is still going on. We present an overview of the existing knowledge regarding these crops and attempt to summarise the numerous constraints that the farmers are now facing. The narrow genetic base of these cultivated plants and their genetic vulnerability is accentuated by pest and pathogens build ups and the rapid environmental changes that are now facing the Pacific islands.
\end{abstract}

KEYWORDS : domestication, environmental changes, genetic vulnerability. 


\section{Introduction}

Il est frappant de constater que du Vanuatu à Hawaii, distants de plus de 6000 kilomètres, les principales espèces cultivées sont identiques (taros, ignames, bananiers, arbre à pain, canne à sucre, kava) et que toutes ont une caractéristique commune, la multiplication végétative exclusive qui empêche leur distribution naturelle sur l'Océan Pacifique. Leur introduction dans une île résultant forcément de l'intervention de l'homme, se pose la question de l'origine géographique de ces plantes et du processus de domestication qui a permis la diversification variétale que l'on observe ici et là. Si toutes ces plantes sont stériles, comment se fait-il que les agriculteurs manipulent, et reconnaissent, autant de variétés différentes? Si le clonage est le seul mode de reproduction, d'où provient la formidable variabilité observée en l'absence de recombinaisons génétiques?

L'origine des plantes cultivées en Océanie a fait l'objet de nombreuses études et publications dont celles, exceptionnelles, de Jacques Barrau. La thèse de doctorat de Barrau (1962) est ellemême une synthèse des connaissances acquises sur le sujet au début des années 1960 alors que les techniques d'investigation reposaient essentiellement sur les enquêtes de terrains, les observations et les identifications botaniques. Les biotechnologies balbutiaient et l'utilisation d'outils moléculaires était encore impossible. La situation a bien changé depuis. Près de 40 ans plus tard, force est de constater que de très nombreux travaux sur la diversité génétique de ces plantes ont été réalisés à l'aide de divers marqueurs et qu'ils contribuent de façon significative à éclaircir le débat et à répondre aux nombreuses énigmes d'ethno-botanique océanienne.

Les inventaires de ressources génétiques conduits ces vingt dernières années visaient essentiellement à constituer des collections nationales de manière à préserver ce patrimoine et à évaluer ses potentialités pour l'amélioration variétale. Bon nombre de pays du Pacifique connaissent en effet un accroissement phénoménal de leurs populations et l'amélioration variétale est vue comme un moyen d'accroître la productivité des systèmes traditionnels et pallier les pressions anthropiques de façon durable. Ces collections variétales ont donc été étudiées en vue d'une amélioration possible des caractères utiles, ce qui suppose que les cultivars soient au préalable décrits au niveau morpho-agronomique et analysés au niveau moléculaire de manière à déterminer la diversité existante et les distances génétiques entre parents potentiels. Même s'ils n'ont pas été conduits dans cette intention, les données résultant de ces travaux révèlent l'histoire de ces cultures traditionnellement océaniennes.

Le présent article vise à synthétiser les connaissances acquises pour les cultures principales (arbre à pain, bananiers, canne à sucre, ignames, kava, taros) et à discuter les hypothèses qu'elles permettent d'énoncer sur l'origine géographique de ces espèces et sur les processus de domestication qui ont conduit aux variétés utilisées aujourd'hui. Ce faisant, nous étudierons les fortes contraintes que rencontrent désormais les insulaires dont les agro-systèmes connaissent de très rapides bouleversements dus notamment aux mouvements de populations et aux changements climatiques, et qui évoluent plus rapidement que leurs plantes.

L'approche pluridisciplinaire est nécessaire pour traiter à la fois de la variabilité génétique et de la diversité des usages chez une espèce cultivée. Il nous sera donc aussi nécessaire d'utiliser certains termes de botanique que nous expliquerons si besoin est.

\section{L'arbre à pain}

L'arbre à pain (Artocarpus altilis) pousse à l'état spontané sur la grande île de NouvelleGuinée où certains individus de plus de trente mètres de hauteur dominent la forêt naturelle des basses terres, sur la côte nord notamment. Parmi les espèces apparentées on trouve Artocarpus camansi des Philippines à Sulawesi jusqu'en Nouvelle Guinée, dont les graines sont également comestibles, et A. mariannensis originaire de Micronésie, limitée à cette zone et qui s'hybride naturellement avec $A$. altilis. Les formes sauvages d' $A$. altilis ne semblent exister qu'en Nouvelle Guinée ; dans le reste de la Mélanésie, il s'agit de formes cultivées. Une première sélection a probablement eu lieu pour conserver par multiplication végétative les arbres dont les fruits produisent des graines appréciées lorsqu'elles sont cuites comme des châtaignes. Ces grosses graines sont d'ailleurs vendues quotidiennement sur les marchés des grandes villes de Madang et de Lae. Les centaines de cultivars ${ }^{1}$ d'arbre à pain présents aujourd'hui en Océanie

1. On nomme cultivar une variété cultivée par opposition aux formes sauvages spontanées. La distinction morphologique entre les nombreux cultivars présents en Océanie, pour une espèce donnée, est faite à l'aide de descripteurs morphoagronomiques dont les différentes modalités sont codées pour permettre leur enregistrement dans des bases de données et faciliter leur analyse multivariée. Ces descripteurs permettent donc de distinguer des morphotypes. 
peuvent être classés en deux grands groupes, les diploides ${ }^{2}$ séminifères ${ }^{3}$ et les triploides toujours aspermes ${ }^{4}$.

Ragone (1991) a conduit une étude de la variabilité génétique de l'arbre à pain à l'aide de six systèmes enzymatiques ${ }^{5}$. Ce travail concernait plus de 200 cultivars originaires de Micronésie, de Polynésie et de Mélanésie. Elle observe que la plus grande diversité génétique réside en Mélanésie. En Micronésie, certaines variétés se révèlent être en fait des hybrides interspécifiques entre $A$. altilis et $A$. mariannensis. En Polynésie, près de 70 cultivars présentent des zymotypes rigoureusement identiques alors que leur variabilité morphologique est très marquée. Ces cultivars sont tous aspermes et triploides. Ils sont multipliés exclusivement par drageons ${ }^{6}$ et certaines mutations somatiques ${ }^{7}$ spectaculaires, mais contrôlées par peu de gènes, sont conservées par les agriculteurs qui souhaitent élargir leur gamme variétale. D'après Ragone (1997) l'origine géographique de l'arbre à pain serait la Nouvelle Guinée ou les îles de l'archipel de Bismarck (Fig. 1). La domestication se poursuit aux Salomons et au Vanuatu où des formes diploides séminifères sont sélectionnées puis clonées, améliorant ainsi la valeur moyenne des populations.

Zerega et al. (2001) ont récemment utilisé des marqueurs $\mathrm{ADN}^{8}$ (AFLP) pour étudier l'origine de l'arbre à pain et leurs résultats confirment ceux de Ragone en ce qui concerne la variabilité génétique de l'espèce. Mais ces auteurs pensent que l'espèce $A$. altilis pourrait être un hybride interspécifique entre $A$. camansi et $A$. mariannensis. Si la phylogénie de l'espèce est encore discutée, son origine géographique est désormais confirmée et se situe dans le nord de la Mélanésie. L'origine des cultivars triploides se situe probablement en Polynésie centrale, à Fidji ou à Samoa. Les quelques triploides actuellement cultivés en Mélanésie sont très probablement d'introduction polynésienne.

\section{Les bananiers}

Le genre Musa est divisé en quatre sections qui comprennent des formes séminifères et aspermes. Deux sections présentent un nombre chromosomique de base de 10 (Callimusa et Australimusa) et les deux autres sections (Eumusa et Rhodochlamys) présentent un nombre de base de 11 chromosomes. La section Australimusa est endémique à l'Océanie et n'existe pas en Asie, elle rassemble les fameux bananier $f e^{\prime} i$ aux régimes érigés, si populaires à Tahiti et aux Marquises. Cette section est en fait originaire de Mélanésie où coexistent des individus sauvages et cultivés.

La grande majorité des cultivars de bananiers appartient à la section Eumusa qui est aussi la plus importante du genre et la mieux distribuée géographiquement. On la trouve de l'Inde à l'Asie du Sud-Est et bien sûr dans le Pacifique. Cette section ne contient pas moins de onze espèces distinctes mais la plupart des cultivars dérivent en fait de deux espèces : Musa acuminata (génome 'A') parfumée et riche en sucre et $M$. balbisiana (génome 'B') fade et riche en amidon. L'espèce $M$. acuminata est très variable et les taxonomistes l'ont subdivisée en une dizaine de sous-espèces dont certaines existent en Nouvelle-Guinée et nulle part ailleurs (Argent, 1976). C'est le cas de M. acuminata ssp. banksii, endémique de la grande île et qui s'hybride fréquemment avec les formes spontanées appartenant aux diverses sous-espèces locales de $M$. acuminata (Sharrock, 1995). Curieusement, on retrouve ssp. banksii à Samoa alors qu'elle est absente du reste de la Mélanésie.

Les graines de bananiers sont nombreuses, de la taille d'une lentille, peu plaisantes au palais et très dures sous la dent. Les premières sélections se sont donc tout naturellement orientées vers les formes parthénocarpiques ${ }^{9}$ de diploides de $M$. acuminata (AA). C'est avant tout la parthéno-

2. Les diploides ont deux jeux de chromosomes, les triploides en ont trois, les tétraploides en ont quatre.

3. Dont les fruits ont des graines.

4. Dont les fruits sont sans graines.

5. Les isoenzymes qui sont des protéines extraites des feuilles, sont utilisés comme marqueurs pour distinguer des zymotypes correspondant à des génotypes déterminés sur la base de leurs profils enzymatiques.

6. Les racines de l'arbre à pain émettent des rejets, appelés drageons, que l'on sectionne pour pouvoir les replanter, il s'agit d'une forme de bouturage.

7. Les mutants somatiques correspondent à des événements accidentels qui se produisent au niveau des bourgeons et autres points de croissance et qui modifient l'apparence morphologique d'un individu en l'absence de recombinaisons sexuées.

8. Les marqueurs ADN permettent enfin de distinguer des génotypes. Tous produisent des empreintes génétiques qui permettent d'identifier très précisément les individus étudiés par rapport à la présence ou absence de bandes séparées par électrophorèse et que l'on nomme des électromorphes. La diversité génétique est appréciée en fonction de la similarité des profils ainsi obtenus. Parmi ces marqueurs ADN, les plus courants sont les RAPD (random amplified polymorphic DNA), les RFLP (restriction fragment length polymorphism) et les AFLP (amplified fragment length polymorphism).

9. La parthénocarpie correspond au développement des fruits sans fécondation normale ni formation de graines. 


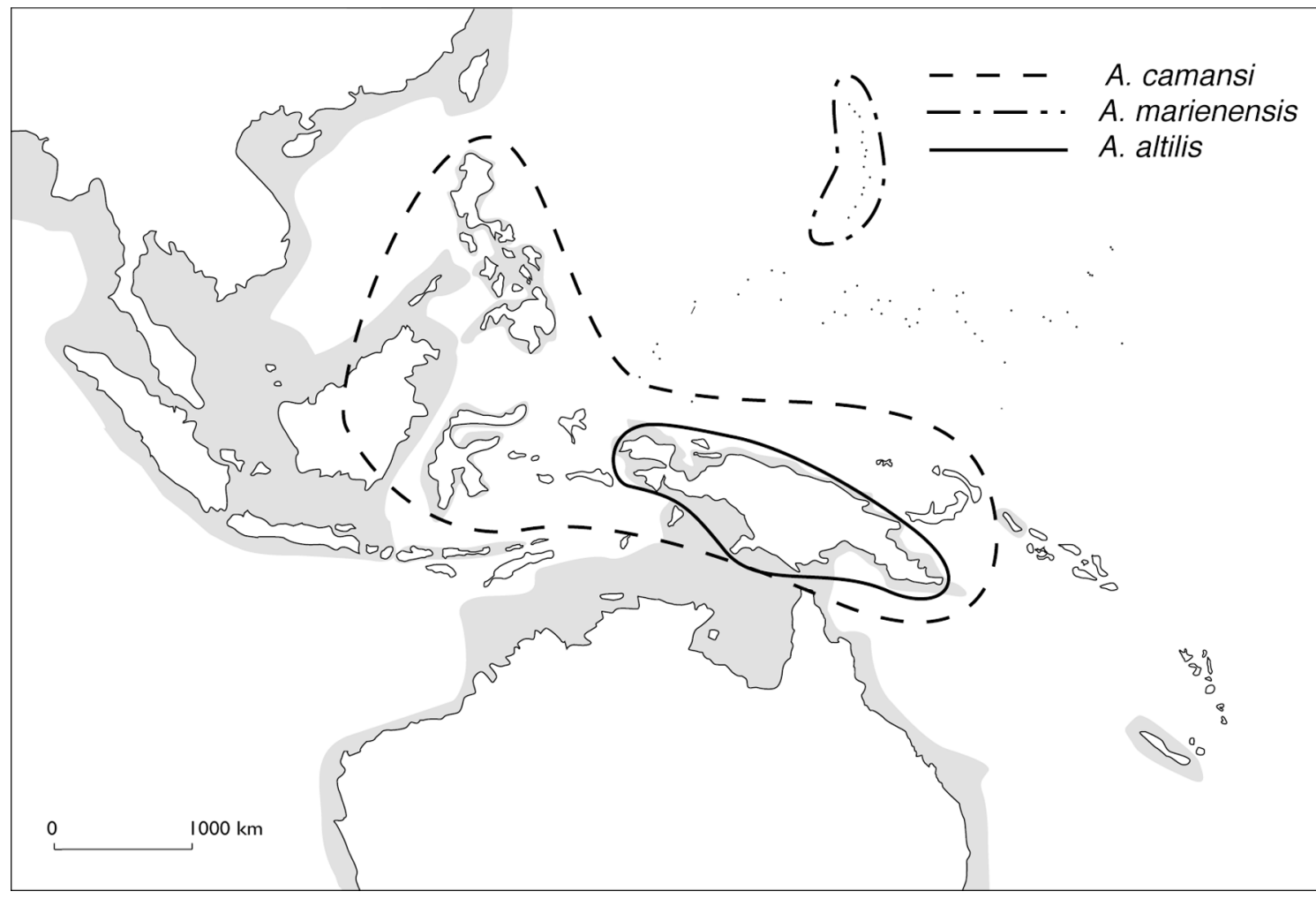

FIG. 1. - Origine géographique de l'arbre à pain et des espèces apparentées. Les zones grisées correspondent aux terres émergées lors de la dernière glaciation, il y a environ 10000 ans.

carpie qui rend une banane attrayante et comestible. Les vigoureux et variés cultivars triploides (AAA) résultent très certainement de croisements entre ces diploides et des individus appartenant à diverses sous-espèces de $M$. acuminata . En Asie du Sud-Est, ces cultivars triploides à gros fruits ont remplacé les cultivars diploides à petits fruits. En Nouvelle-Guinée cependant, les diploides ont toujours une réelle importance et on rencontre une riche et spectaculaire agrobiodiversité. Les cultivars diploides et triploides de $M$. acuminata ont, à un moment ou un autre de leur histoire, échangé du pollen avec M. balbisiana pour donner naissance à des formes interspécifiques hybrides cultivées diploides $(\mathrm{AB})$, triploides $(\mathrm{AAB}, \mathrm{ABB})$ et même tétraploides (AAAB, AABB, ABBB).

Les études de diversité que nous avons conduites à l'aide d'isozymes (Lebot et al., 1993) ont révélé les relations phylogénétiques existantes entre 563 cultivars de Musa récoltés dans toute l'Océanie et comprenant aussi bien des diploides (AA, AB, BB), des triploides (AAA, AAB, ABB) que des tétraploides (AAAB, $\mathrm{AABB}$ ). Les analyses multivariées différencient clairement les groupes selon leurs compositions génomiques et montrent que les formes sauvages de M. acumi- nata présentes en Nouvelle-Guinée se distinguent nettement des formes asiatiques, l'isolement géographique étant probablement responsable d'une dérive génétique. Les zymotypes observés confirment les conclusions des botanistes : les diverses sous-espèces de M. acuminata se sont fréquemment hybridées localement. Ces marqueurs révèlent aussi que des triploides AAA sont probablement des sélections réalisées sur place à partir de diploides AA endémiques, sauvages ou cultivés.

Les variétés de bananiers les plus cultivées en Océanie appartiennent au groupe dénommé " plantains du Pacifique » dans la nomenclature internationale. Il s'agit de trois variétés triploides $\mathrm{AAB}$ dont les régimes portent de gros fruits de bananes à cuire et qui sont des plantes alimentaires de base, en Mélanésie notamment. On les trouve le long des routes, dans les jardins et sur les marchés de Port Moresby, Honiara, Port Vila, Nouméa et Suva. Si elles y ont désormais perdu de l'importance, elles étaient très consommées dans toute la Polynésie lors de l'arrivée du Capitaine Cook. Ces variétés sont connues des experts sous leurs noms Hawaiiens de maia maoli, popo'ulu et iholena. La maoli (= banane maori) est la variété à plus gros fruits, elle corres- 
pond aux mao'i des Marquises, aux ma'ohi de Tahiti et à la banane chef de Nouvelle-Calédonie. Les popo'ulu sont ces grosses bananes aux fruits courts et trapus, parfois aussi longs que larges, connus sous le nom de po'uà Tahiti, de po'upo'u aux Marquises et de poingo en NouvelleCalédonie. Enfin les iholena de Hawaii, ou ore'a à Tahiti, sont remarquables pour leur chair très orangée qui, comme pour les $f e^{\prime} i$, donne une couleur jaune fluorescente à l'urine qui surprend les consommateurs, y compris les habitués. À l'intérieur de chacune de ces variétés, maoli, popo'ulu ou iholena, les agriculteurs différencient de nombreux morphotypes en fonction des couleurs de la plante, de l'épiderme ou de la chair des fruits.

L'origine géographique de ces variétés a longtemps préoccupé les spécialistes (Stover and Simmonds, 1987) parce que rien de comparable n'existe en Asie. Nos travaux à l'aide d'isozymes démontrent que les trois variétés maoli, popo'ulu et iholena sont très proches génétiquement bien que morphologiquement très différentes (Lebot et al., 1993). À l'intérieur de chaque variété, les morphotypes, connus sous des appellations vernaculaires distinctes par les agriculteurs, sont des mutants somatiques sélectionnés par clonage. Les agriculteurs ont donc diversifié morphologiquement leurs variétés par clonage. Les isozymes indiquent que la contribution acuminata au génome de ces plantes serait en fait une contribution de la sous-espèce $M$. acuminata ssp. banksii, ce qui laisse entendre que la domestication aurait eu lieu soit dans la grande île de Nouvelle-Guinée soit en Mélanésie insulaire, mais certainement pas en Asie d'où cette sous espèce est absente.

Carreel (1994) a étudié la diversité génétique des bananiers à l'aide de marqueurs RFLP et a confirmé les résultats que nous avons obtenus à l'aide d'isozymes. Elle a aussi montré que l'espèce $M$. schizocarpa, endémique de NouvelleGuinée, était très proche de $M$. acuminata et que plusieurs cultivars étaient en fait des hybrides naturels entre les deux espèces. Ses résultats confirment par ailleurs que de nombreux cultivars diploides parthénocarpiques originaires de Nouvelle-Guinée ont en fait une contribution ssp. banksii à leurs génomes et sont donc forcément des sélections locales (Fig. 2). D'après Carreel (1994), le caractère déterminant pour la domestication, la parthénocarpie, proviendrait des génomes soit banksii soit errans, deux sousespèces endémiques à la Nouvelle-Guinée, ce qui laisserait supposer une origine sur cette grande île pour les plus anciennes variétés de bananiers.

\section{La canne à sucre}

Saccharum officinarum n'existe qu'à l'état cultivé et son centre de diversification est incontestablement la Nouvelle-Guinée (Daniels et Roach, 1987). Le naviso du Vanuatu, Saccharum edule, cultivé pour ses inflorescences avortées ${ }^{10}$ très appréciées en saison, n'existe qu'en Mélanésie et serait le résultat d'introgressions ${ }^{11}$ entre $S$. officinarum et $S$. robustum, cette dernière existant à l'état sauvage de Bornéo au Vanuatu. Toujours d'après Daniels et Roach (1987), $S$. robustum serait un complexe d'espèces qui comprend des populations spontanées dérivées d'introgressions entre $S$. spontaneum et d'autres genres (Erianthus et Miscanthus) présents dans une région allant des îles de la Sonde à la Nouvelle-Guinée. Ces auteurs concluent que $S$. robustum est l'ancêtre probable de la canne à sucre et que celle-ci aurait été domestiquée en Nouvelle-Guinée. Des sélections répétées, opérées par des populations habituées à mastiquer des cannes pour leurs teneurs en jus sucré, auraient ainsi conservé par clonage des formes de $S$. officinarum à faibles teneurs en fibres. Les cultivars ont ensuite été différenciés en de nombreux morphotypes distincts par sélection de mutants somatiques.

Wood (1988) s'est intéressée à la variabilité génétique des cultivars de $S$. officinarum présents dans le Pacifique en utilisant des isozymes comme marqueurs. Ses résultats démontrent que leur base génétique est effectivement très étroite. Glaszmann et al. (1989) ont également criblé, pour leur variabilité isoenzymatique, un grand nombre de cultivars de canne à sucre ainsi que des accessions appartenant à des espèces apparentées. Ils observent que les analyses multivariées permettent de différencier clairement les espèces. Plus récemment, Lu et al. (1994) ont utilisé des RFLP et confirmé que si les espèces pouvaient être effectivement différenciées, la variabilité intraspécifique était très variable chez chacune d'elles. Elle est forte pour $S$. spontaneum, intermédiaire pour $S$. robustum et limitée pour $S$. officinarum. Leurs résultats confirment les classifications taxonomiques mais indiquent que $S$. robustum et $S$. officinarum sont très proches. Une domestication directe de S. officina-

10. Ces inflorescences, comparables à des brocolis, n'arrivant jamais à maturité sont incapables de former des graines. Elles sont vendues et cuites dans leurs gaines et agrémentées de lait de coco.

11. Échanges et fixations de gènes. 


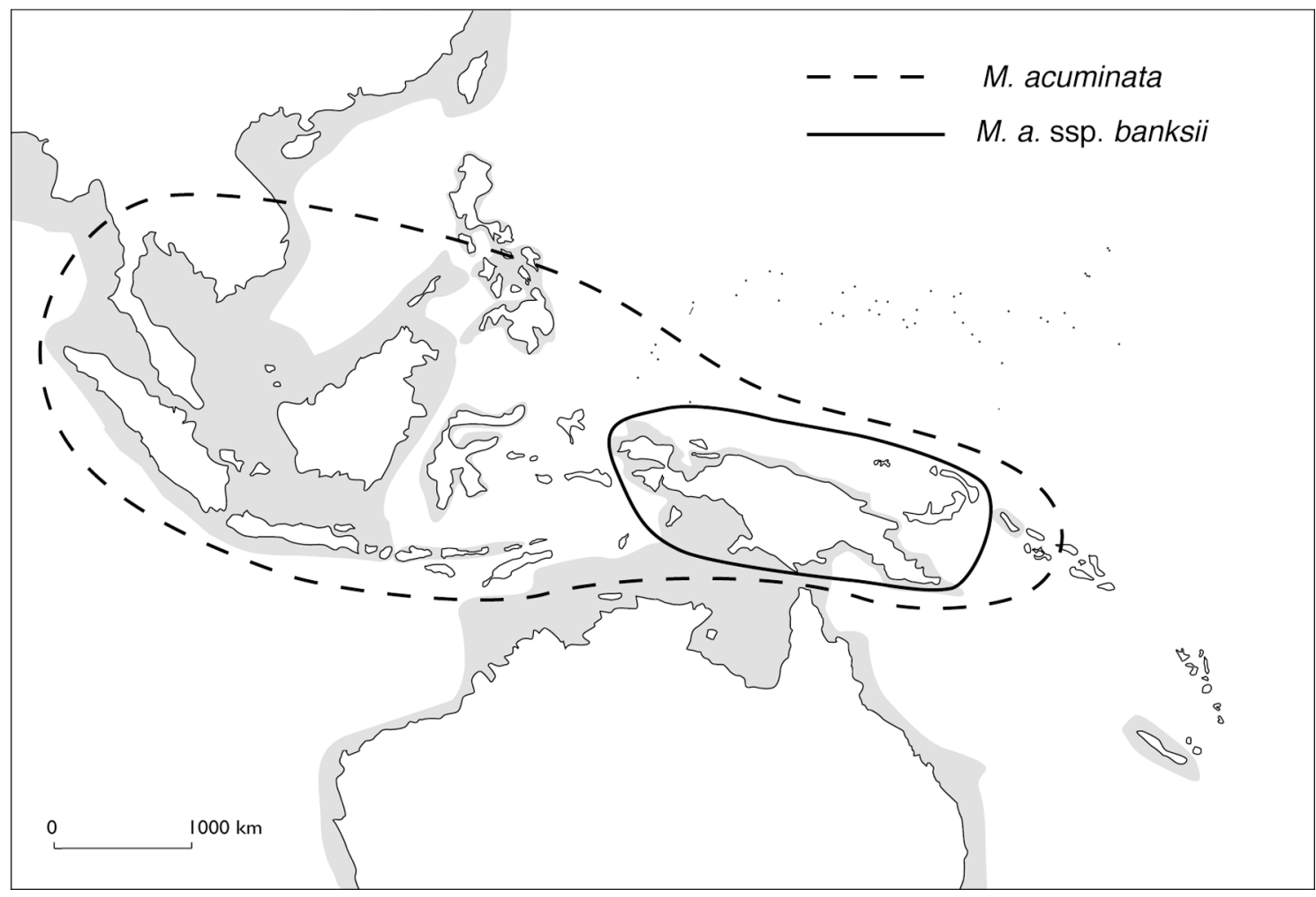

FIG. 2. - Origine géographique de la sous-espèce de Musa ayant contribué au génome des variétés de bananiers du Pacifique.

rum à partir de $S$. robustum est cependant exclue parce que certains électromorphes ${ }^{12}$ présents chez les cultivars sont absents chez $S$. robustum mais existent chez $S$. spontaneum et même chez les genres Erianthus et Miscanthus.

De toutes les espèces, $S$. spontaneum est certainement la moins manipulée des Saccharum spp. Elle est distribuée du Sud-Est Asiatique à la Papouasie Nouvelle-Guinée et aux Salomons. Si on en juge par les données RFLP, les cultivars de $S$. officinarum sont très probablement dérivés d'introgressions entre des formes sauvages mélanésiennes de $S$. robustum et de $S$. spontaneum, ce qui confirme l'hypothèse d'une domestication opérée en Nouvelle-Guinée (Fig. 3). De son côté, $S$. edule exhibe des profils RFLP très similaires à $S$. robustum, ce qui confirme la contribution de cette dernière espèce à son génome. Puisque $S$. edule n'existe nulle part ailleurs, il est fort probable qu'elle fut domestiquée localement à partir de formes sauvages de $S$. robustum endémiques de Mélanésie.

\section{Les ignames}

Les ignames ont une valeur culturelle et coutumière considérable en Mélanésie. Ces plantes annuelles sont dotées d'une horloge biologique interne qui alterne des phases de développement végétatif et de dormance ${ }^{13}$. Les cycles de culture de l'igname dictent donc les rythmes et certains rites des sociétes rurales d'Océanie. Il est probable que l'igname soit l'une des plus anciennes plantes domestiquées dans cette région. Mais l'appellation prête à confusion parce que des espèces distinctes et d'origines géographiques différentes se cachent derrière ce même terme. On rencontre dans les jardins du Pacifique, pas moins de neuf espèces : Dioscorea alata, D. bulbifera, D. cayenensis, D. esculenta, D. hispida, D. nummularia, $D$. pentaphylla, $D$. transversa et $D$. trifida. Toutes sont cultivées mais il existe aussi, en Nouvelle-Guinée et en Australie, de nombreuses espèces de Dioscoreaceae que l'on rencontre à l'état spontané et dont certaines n'ont toujours pas été identifiées. La $D$. transversa connue sous le nom de wael en Nouvelle-

12. Un électromorphe correspond à l'une des nombreuses bandes qui sont séparées par électrophorèse dans un champ électrique et qui permettent de visualiser la variabilité moléculaire.

13. Période de quelques mois durant laquelle les tubercules sont conservés en greniers en attendant qu'ils germent avant d'être replantés. 


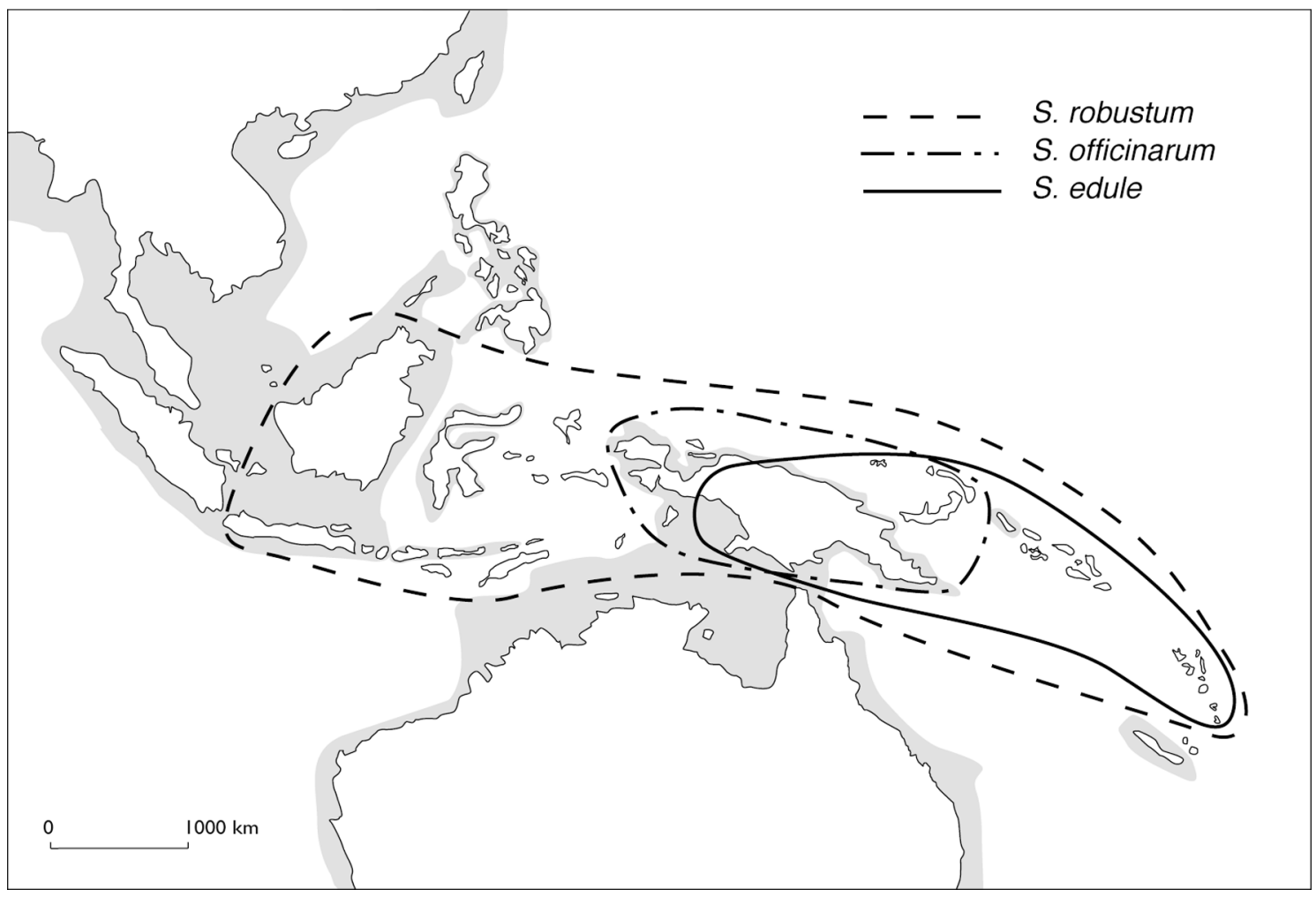

FIG. 3. - Origine géographique des espèces apparentées à la canne à sucre.

Calédonie, n'a de réelle importance que dans ce Territoire où elle tend cependant à disparaitre des jardins. Les ignames $D$. cayenensis et $D$. rotundata sont originaires d'Afrique et ont été introduites au vingtième siècle, leur diversité génétique se limite à quelques clones. L'igname antillaise $D$. trifida, connue sous le curieux nom de africa au Vanuatu, est également d'introduction récente et un seul clone est cultivé.

L'igname douce $D$. esculenta, appelée wovilé en français du Pacifique, est supposée d'origine asiatique (Coursey, 1976) mais exhibe une variabilité morphologique impressionnante pour une espèce qui ne produit jamais de fleurs ni de graines. Sa date d'introduction dans le Pacifique reste obscure et il est probable qu'elle soit bien plus ancienne qu'on ne le suppose. Certaines formes présentent en effet des caractères primitifs tels que la présence d'épines sur les racines pour se protéger des prédateurs. Leur récolte demande un certain doigté. Les ignames $D$. nummularia et $D$. pentaphylla sont incontestablement des espèces mélanésiennes et on rencontre dans cette région des formes sauvages fertiles en forêt primaire et des cultivars dans les jardins. La domestication et la sélection de ces espèces semble être un processus qui se poursuit actuellement. L'espèce $D$. hispida est exploitée en période de disette et l'aire de distribution de ses formes sauvages va du Vietnam à la Mélanésie en passant par l'Indonésie (Fig. 4). Certains individus peuvent être très toxiques. Le $D$. bulbifera est une espèce pantropicale que l'on retrouve dans l'ancien et le nouveau monde et en Australie.

L'origine géographique de la grande igname, la $D$. alata, a fait couler beaucoup d'encre (Degras, 1986) et reste encore une énigme. Il s'agit certainement de l'espèce cultivée la mieux distribuée géographiquement et dont le potentiel agronomique intéresse le plus les agriculteurs compte tenu de ses qualités, de sa facilité de culture et de conservation. On la rencontre désormais aussi bien en Asie du Sud-Est, au Philippines notamment, en Inde, en Afrique ou aux Antilles et en Amérique du Sud. Sa variabilité morphologique est tout simplement phénoménale et le nombre de cultivars existant sur la planète aujourd'hui se compte par plusieurs centaines. Cette espèce n'a jamais été trouvée à l'état sauvage et on ne sait pas si elle peut s'hybrider avec d'autres Dioscoreaceae. Certains auteurs (Coursey, 1976 ; Hahn, 1987) pensent qu'il s'agirait d'un ensemble de cultivars sélectionnés directement à partir de formes sauvages disparues aujourd'hui bien que rien ne leur permette d'avancer une telle hypothèse. D'autres suggèrent qu'il s'agirait d'un hybride interspécifique 


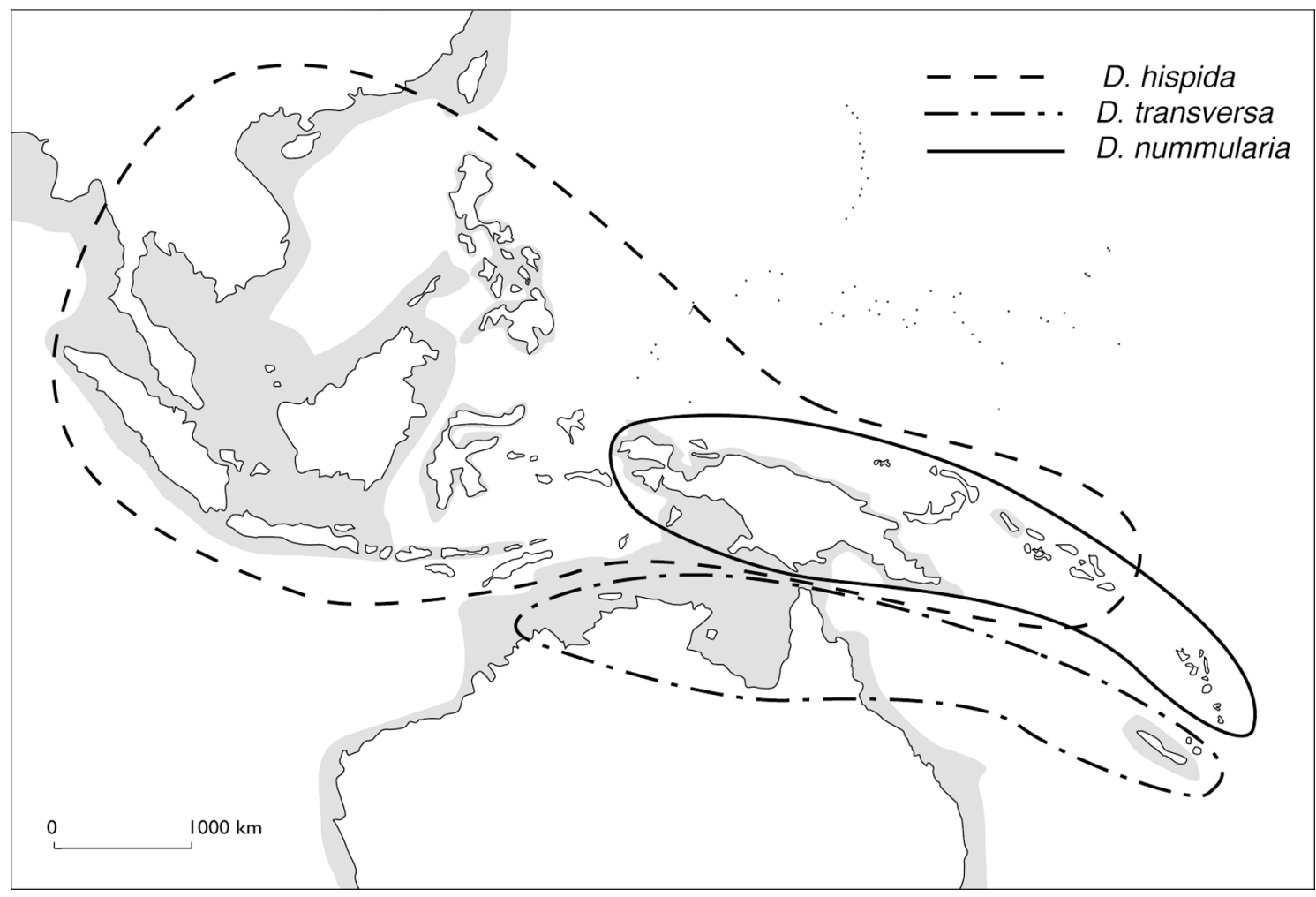

Fig. 4. - Origine géographique des Dioscoreaceae cultivées endémiques du Pacifique.

entre $D$. hamiltonii et de $D$. persimilis, probablement originaire d'Indochine où ces deux espèces coexistent (Barrau, 1962), d'autres encore observent très justement que le centre de diversité se trouve très certainement en Mélanésie (Martin et Rhodes, 1977).

L'espèce $D$. alata rassemble des cultivars tétraploides, hexaploides et octoploides mais les formes diploides n'ont jamais été décrites. La plante est par ailleurs dioique ${ }^{14}$, les fécondations supposent donc que des individus de sexe opposés, dont les floraisons sont synchrones, puissent bénéficier de vecteurs polliniques efficaces ${ }^{15}$. Les agriculteurs ne connaissent pas les graines et observent très rarement des fleurs. Les collections existantes en Mélanésie rassemblent pourtant de très nombreux morphotypes distincts dont l'origine pose donc un problème. Nous avons tenté de clarifier la question (Lebot et al., 1998) en étudiant la variabilité génétique de 269 variétés d'origines géographiques diverses à l'aide d'isozymes. Les zymotypes obtenus indiquent que des fécondations croisées ont bien eu lieu à un moment ou un autre du processus de domestication. Si la variabilité génétique est limitée en Afrique, ou même en NouvelleCalédonie où l'on trouve pourtant 131 morphotypes, elle apparaît plus importante dans le nord de la Mélanésie.

Nous avons récemment contribué à la mise en place de collections nationales en Papouasie Nouvelle-Guinée, aux Salomon, au Vanuatu et à Fidji. Ces collections rassemblent désormais des centaines de cultivars décrits à l'aide de descripteurs morpho-agronomiques standardisés et qui permettent les comparaisons d'un pays à l'autre. $\mathrm{Au}$ Vanuatu, la collection comporte quelques accessions dont l'identification botanique est délicate compte tenu de leur ressemblance à $D$. nummularia : ailes de la tige atrophiées, présence d'épines saillantes à la base de la tige. Malapa (2000) a utilisé des marqueurs AFLP pour étudier la diversité existant au Vanuatu et comparer les profils à d'autres espèces présentes en collection (D. bulbifera, D. cayenensis, D. esculenta, D. nummularia, D. pentaphylla, D. rotundata et $D$. tri$f i d a)$. Les résultats obtenus et leur analyse multivariée montrent que $D$. alata est beaucoup plus

14. Une espèce dioique présente des fleurs mâles sur un plant et des fleurs femelles sur un autre plant. L'espèce est monoique, lorsque les deux sexes sont présents sur le même plant.

15. Le vent ne peut disperser ce pollen peu abondant et collant aux fleurs, les insectes attirés par celles-ci sont rares, voire inexistants dans certains pays. 
proche du D. nummularia qu'elle ne l'est des autres espèces. Il semble donc probable que le $D$. nummularia rassemble certaines des formes ancestrales du D. alata.

On ne connaît pas grand chose du D. nummularia, la variabilité de ses niveaux de ploidie est inconnue et on ne sait si les diploides existent. Cette espèce connue au Vanuatu comme wild yam ou strong yam est présente dans toutes les îles de Mélanésie à l'état spontané mais aussi cultivé (Fig. 4). Au Vanuatu se trouvent des formes sauvages, pour ainsi dire pérennes, dont les énormes tubercules produisent en forêt de nouvelles tiges tous les ans et qui sont entretenues et protégées pour des raisons de sécurité alimentaire mais aussi pour être utilisées comme offrandes, sur l'île de Malekula notamment. Certains cultivars très améliorés ressemblent aussi au $D$. alata en ce qui concerne les caractéristiques de leur chair. Elles sont très appréciées des consommateurs de laplap ${ }^{16}$ surtout en raison de la blancheur immaculée du produit obtenu après cuisson. C'est le cas du célèbre cultivar marou, originaire de l'île de Malo, qui disparaît très rapidement du marché de Port Vila lorsqu'il y est vendu une fois l'an.

Terauchi et al. (1991) ont utilisé des marqueurs RFLP pour étudier la diversité génétique du D. bulbifera et Ramser et al. (1996) ont fait de même à l'aide de marqueurs RAPD. Ces deux équipes se sont intéressées aux distances génétiques existantes entre génotypes originaires d'Afrique, d'Asie et du Pacifique. Leurs conclusions sont concordantes : en Océanie, les formes cultivées de $D$. bulbifera trouvent leur origine chez les formes sauvages endémiques de la même espèce et sont très distantes des génotypes asiatiques et africains. Dans ce cas précis, la domestication s'est opérée localement en sélectionnant des formes non toxiques pour les mettre en culture à l'aide de bulbilles ${ }^{17}$ récoltées en forêt.

\section{Le kava}

La question de l'origine du kava (Piper methysticum), la boisson traditionnelle des peuples du Pacifique, a fasciné bon nombre de chercheurs depuis des décennies. La question est d'autant plus intéressante que le kava n'existe pas ailleurs, ni en Asie du Sud-Est ni en Améri- que du Sud, et que sa distribution géographique en Océanie est elle-même énigmatique, contrairement aux autres grandes plantes. Le kava existe en Nouvelle-Guinée mais à l'état de curiosité dans de rares villages isolés où il fait l'objet d'une consommation occasionnelle, contrairement aux autres pays insulaires. Il n'a jamais réussi à se développer dans la grande île bien que son introduction remonte très certainement à plus d'un siècle. Le kava n'existe pas dans l'archipel des Bismark ni aux îles Salomons mais des retours polynésiens l'ont introduit à Vanikoro et Tikopia. En Micronésie, on ne le trouve qu'aux Carolines, à Ponape et Kosrae. Il a été cultivé dans toutes les îles où les Polynésiens ont installé des colonies et où les conditions pédoclimatiques permettaient sa croissance. Bien qu'introduit en Nouvelle-Calédonie, sa culture y est très difficile en raison des basses températures (Lebot et al., 1992).

Les inventaires de ressources génétiques que nous avons conduits au début des années 1980 nous ont permis de répondre à bon nombre d'interrogations. D'un point de vue morphologique d'abord, il existe dans le Pacifique environ 120 morphotypes de kava correspondant à des variétés connues sous des appellations locales en langues vernaculaires. Au Vanuatu, il existe plus de 240 noms variétaux qui correspondent en fait, après descriptions morpho-agronomiques, à environ 80 morphotypes. Il est difficile, sur la base de caractères purement morphologiques, de classer les cultivars en grands groupes. D'une manière générale cependant, les cultivars polynésiens se distinguent des mélanésiens par leur esthétisme, leurs couleurs attrayantes et les entre-nœuds extrêmement courts de certains d'entre eux. Au Vanuatu, la variabilité morphologique est pour ainsi dire continue et bon nombre de morphotypes semblent toujours en voie de sélection. Dans ce pays, la diversité des usages est probablement une résultante de la diversité et de la richesse culturelle. Le kava est à la fois une boisson quotidienne, une plante médicinale, une offrande coutumière, un médium de communication avec les ancêtres et, de nos jours, la première culture de rente (Siméoni, 1998).

Une étude chimio-taxonomique (Lebot et Lévesque, 1989), conduite sur toutes les variétés du Vanuatu et du Pacifique, a permis, en quanti-

16. Le laplap est le plat national du Vanuatu et correspond à une pâte obtenue après cuisson à l'étouffée de tubercules, de bananes ou de fruits à pain broyés très finement et enveloppés dans une feuille laplap (Heliconia indica).

17. Les bulbilles sont de petits tubercules aériens attachés directement aux tiges, leur plantation est une forme de multiplication végétative donnant des individus identiques au pied mère. 


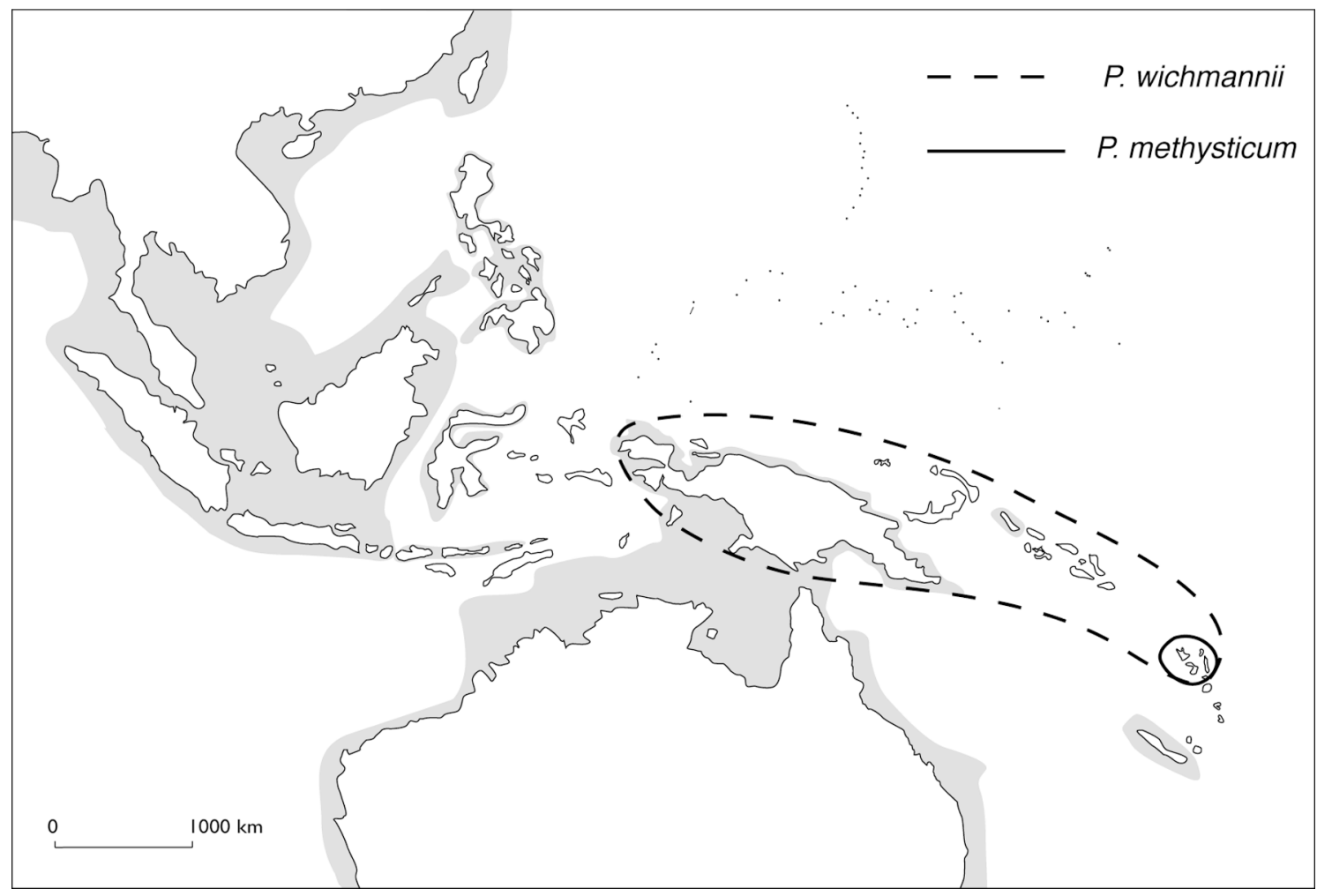

FIG. 5. - Aires d'origine et de domestication du kava.

fiant les six molécules majeures (des kavalactones ${ }^{18}$ ) d'identifier des chimiotypes ${ }^{19}$, c'est-àdire des groupes de cultivars affines d'un point de vue chimique. Certains chimiotypes correspondent à des usages quotidiens sous la forme d'une boisson relaxante, d'autres à des usages médicinaux. Le caractère utile de la plante, le chimiotype, est donc directement corrélé avec les usages qui en sont faits. Un groupe de chimiotypes particuliers correspond à des formes connues pour être le kava que buvaient les ancêtres, qui est aussi l'ancêtre des kavas d'aujourd'hui. Ces formes appartiennent à l'espèce sauvage, le Piper wichmannii, qui correspond en fait à un artefact taxonomique. Le $P$. wichmannii est endémique de la Mélanésie mais n'a jamais été récolté en Indonésie ou en Nouvelle-Calédonie et Fidji (Fig. 5). Le processus de domestication du kava peut se décrire comme étant une sélection par voie clonale de chimiotypes sans cesse améliorés, du $P$. wichmannii spontané en forêt aux cultivars nobles et très appréciés. Chaque récolte individuelle de plant consommé par les agriculteurs fait l'objet d'une sélection pratiquement quoti- dienne. La pression est donc très forte, et si la stérilité de l'espèce écarte l'accès aux recombinaisons génétiques, les buveurs ne manquent pas de remettre en culture les mutations qui les intéressent.

Les données obtenues par la chimiotaxonomie ont été corroborées à l'aide de marqueurs isozymes (Lebot et al., 1991). Si la variabilité morphologique est remarquable et facilement appréciable, la variabilité chimique l'est tout autant mais la variabilité révélée au niveau enzymatique démontre une étroitesse de la base génétique. Le $P$. methysticum est un décaploide ${ }^{20}$ stérile et l'espèce est dioique, ce qui signifie que les pollinisations font forcément intervenir des individus différents. Des fécondations devraient donc donner des individus fortement hétérozygotes; or, les trois zymotypes, qui rassemblent les 118 accessions étudiées, sont extrêmement proches. Ce qui frappe le plus, c'est la quasi absence de variabilité génétique au sein des cultivars de $P$. methysticum qui apparaissent comme dérivant d'un seul individu par voie clonale. Les isozymes indiquent que les premières sélections se sont

18. Les kavalactones sont les molécules responsables des propriétés physiologiques du kava : anxiolitique, décontractant et relaxant musculaire.

19. Le chimiotype est déterminé en codant les six kavalactones majeures en fonction de leur ordre décroissant dans l'extrait obtenu à l'aide de solvants volatiles.

20. Le kava possède dix jeux de 13 chromosomes. 
très certainement opérées dans le nord de l'archipel du Vanuatu. Il est possible qu'une diversification secondaire ait ensuite eu lieu en Polynésie occidentale pour donner naissance à des chimiotypes enrichis en une kavalactone particulière, la methysticine, et qui n'existent pas au Vanuatu.

Des marqueurs AFLP ont été utilisés (Lebot $e t$ $a l ., 1999)$ pour tenter de différencier des individus exhibant des zymotypes identiques et, malgré le nombre de marqueurs testés, il est démontré que les morphotypes sont des mutations somatiques conservées par clonage. Cette sélection de chimères ${ }^{21}$ a toujours cours au Vanuatu où les agriculteurs très observateurs jouent à trouver de la variabilité dans leurs jardins. La très faible variabilité génétique du kava est une indication de sa relative jeunesse par rapport aux autres grandes plantes traditionnelles d'Océanie, il aurait probablement moins de 3000 ans, si on en juge par la date approximative d'arrivée des Mélanésiens dans les îles.

\section{Le taro et les autres aracées}

Les aracées endémiques et cultivées dans le Pacifique concernent quatre espèces : Alocasia macrorrhiza, Amorphophallus paeoniifolius, Cyrtosperma chamissonis et, bien sûr, le Colocasia esculenta. Ces quatre espèces présentent des formes cultivées et sauvages, les formes spontanées existant uniquement dans les grandes îles de Mélanésie. Les grands taros, $A$. macrorrhiza et $C$. cyrtosperma, sont des spécificités exclusivement océaniennes et ne sont pas cultivés en Asie du Sud-Est. Le premier est une plante alimentaire de base en Polynésie occidentale, surtout à Wallis, Futuna, Samoa et Tonga et le second reste très important dans l'alimentation des Micronésiens.

On trouve dans la littérature de nombreuses références indiquant une origine entre l'Inde, le Bangladesh et le Myanmar pour le taro Colocasia esculenta (Plucknett 1976), sans que rien ne puisse réellement le démontrer. Le taro pousse à l'état spontané dans toute l'Asie du Sud-Est, en Indonésie et dans les îles de la Sonde. On sait depuis les travaux de Matthews (1990) qu'il existe des populations sauvages de $C$. esculenta dans les Territoires du Nord de l'Australie et qu'elles présentent toutes les caractéristiques d'une espèce endémique. Nous avons récemment étudié des populations sauvages de $C$. esculenta en Nouvelle-Calédonie (Ivancic et Lebot, 1999) et des formes spontanées existent également dans les grandes îles mélanésiennes des Salomons et du nord du Vanuatu.

Les agriculteurs du Pacifique qui cultivent des formes stériles ne connaissent pas les fruits ni les graines du taro. Les inventaires de ressources génétiques montrent pourtant qu'il existe des milliers de cultivars avec un nombre décroissant par pays d'ouest en est. À Hawaii, par exemple, on compte près d'une centaine de morphotypes distincts connus sous des appellations différentes et dont la variabilité morphologique est tout à fait remarquable. Les études sur la variabilité enzymatique montrent cependant qu'elle est nulle. Dans le cas précis de cet archipel, les nombreux cultivars résultent d'une différentiation par voie asexuée (Lebot et Aradhya, 1991). Nous avons étendu cette étude à plus de 1100 cultivars originaires d'Indonésie, de Mélanésie et de Polynésie. Les résultats montrent que l'Indonésie est certainement le pays qui abrite la plus grande variabilité génétique mais que la NouvelleGuinée est, elle aussi, un foyer important alors que les îles de Polynésie connaissent des bases génétiques extrêmement étroites (Lebot et Aradhya, 1991). En Asie du Sud-Est, la variabilité isoenzymatique est beaucoup plus grande et témoigne des flux de gènes entre formes cultivées et sauvages. Elle indique aussi que les cultivars des deux régions, Asie du Sud-Est et Pacifique, ont très certainement fait l'objet de domestications indépendantes à partir de populations sauvages locales déjà différenciées génétiquement (Fig. 6).

Les récents travaux conduits à l'aide de marqueurs AFLP (Krieke et al. 2001) sur un échantillon représentatif de plus de 200 individus sélectionnés à partir de leurs zymotypes, révèle une plus grande variabilité existant au sein des cultivars originaires du sud-est asiatique. Elle indique aussi une structuration géographique de cette variabilité avec des groupes de cultivars affines correspondant exactement aux pays et indiquant donc une absence d'échanges de matériel végétal, probablement du fait de l'isolement insulaire qui caractérise cette vaste zone géographique. Elle confirme enfin des domestications multiples et indépendantes. Le taro est certainement l'une des plus anciennes plantes cultivées, et ses domestications ont très certainement été multiples et répétées, dans l'espace comme dans le temps.

21. On appelle une chimère un plant dont la morphologie est anormale par rapport au pied mère dont il est issu par clonage. 


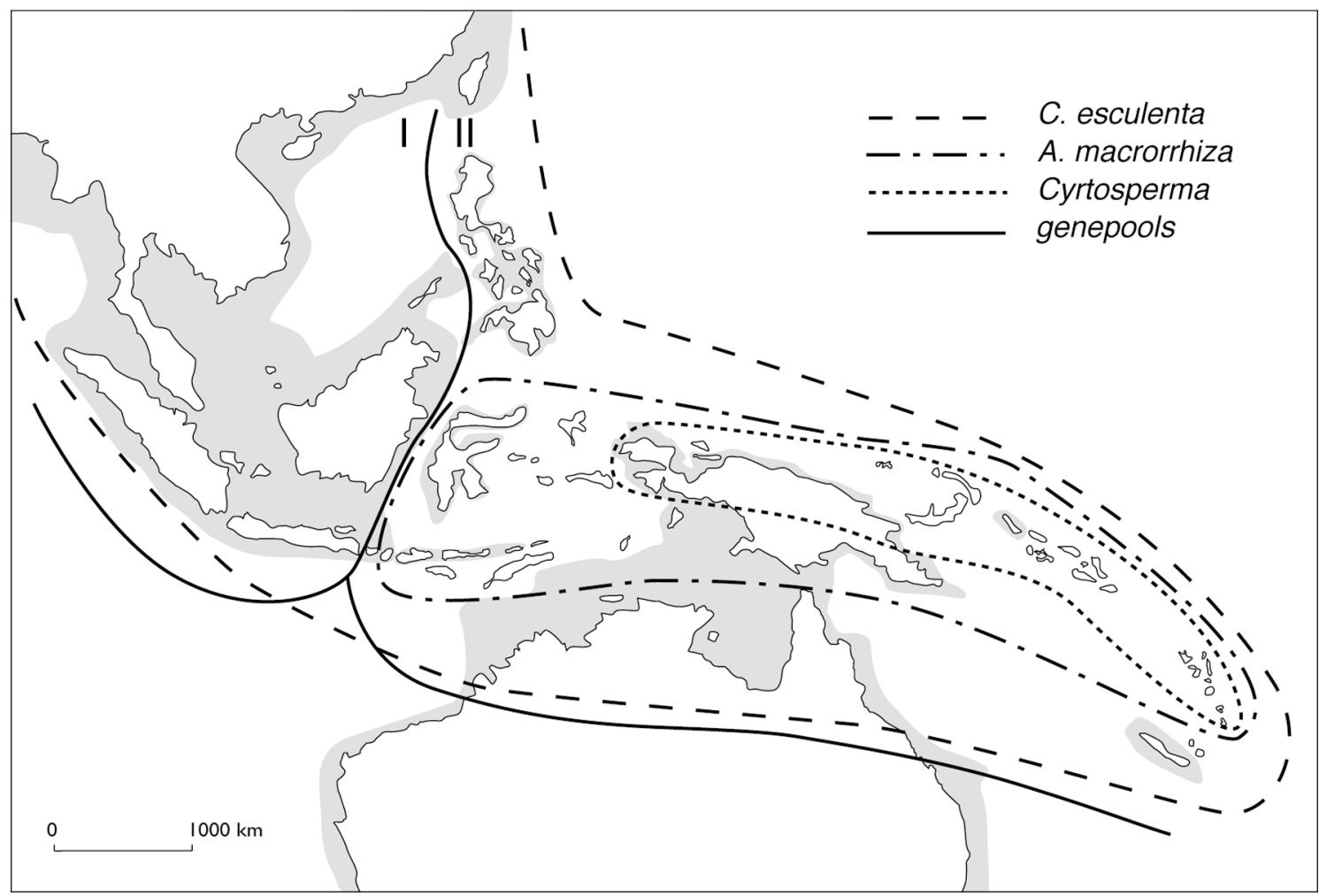

Fig. 6. - Distribution des principales Araceae cultivées dans le Pacifique.

\section{Des origines sur Sahul plutôt que sur Sunda}

La question de l'origine des plantes cultivées en Océanie a longtemps fait l'objet de controverses et de discussions passionnées en raison de l'absence de données objectives permettant de trancher entre les diverses hypothèses. Parmi les voies d'introduction possibles, Barrau (1962) a proposé deux itinéraires partant d'Asie, la « route du nord » via la Micronésie et la « route du sud » via la Nouvelle-Guinée. Yen (1991a et b) a présenté et discuté des éléments nouveaux, apportés par les recherches archéologiques et ethnobotaniques notamment, et qui suggèrent des domestications possibles ailleurs que dans le foyer asiatique. Il ne manque pas d'indiquer le nord de Sahul comme aire d'origine des cultures traditionnelles, en s'appuyant sur la biogéographie des espèces et l'ancienneté de leurs usages (Yen 1993).

L'étude de l'histoire des espèces alimentaires fait effectivement appel aux travaux des archéologues qui retrouvent sur leurs sites des graines ou des coquilles de noix attestant de la consommation d'une plante à une époque dont la date est précisément déterminée par le carbone 14 ou par d'autres mesures objectives. Si cette approche est valable pour les céréales ou les plantes à graines et à fruits d'une manière générale, elle devient inutilisable pour les plantes à multiplication végétative dont les organes utiles retournent très rapidement à l'état de matière organique en zone tropicale humide. En Océanie, il est difficile de retrouver sur les sites archéologiques des traces d'aliments consommés à l'ère préhistorique en raison de leur rapide décomposition. On ne retrouve rien au fond des poteries Lapita (Kirch, 1997), ni graines de céréales, ni traces de tubercules.

L'origine asiatique des populations qui ont colonisé l'Océanie a laissé croire que ces populations auraient pu introduire le riz avec elles à un moment ou un autre de leur histoire, mais on ne retrouve pas non plus de traces de cette céréale sur ces sites (Kirch, 1997; Spriggs, 1997). Domestiquée il y a environ 6000 ans (Jacquot et al., 1997), cette plante est facile à conserver et à multiplier, et il serait normal que des migrants s'en munissent lors de leurs pérégrinations, à moins qu'ils ne partent d'un endroit d'où le riz n'existe pas ou n'a pas encore été inventé. Les Austronésiens ont certainement introduit le riz à Madagascar et il est normal d'envisager qu'ils aient tenté d'en faire autant en Océanie (Bellwood, 1985 ; Blust, 1985). Ils l'ont peut être rapidement abandonné devant les performances exceptionnelles des cultures domestiquées par 
les peuples qu'ils ont rencontrés en arrivant sur ces îles. Tout indique qu'ils leur ont même emprunté ces plantes pour les emmener sur leurs pirogues, très loin et jusqu'à Hawaii au moins.

On pense que les premiers hommes à avoir colonisé la plaque continentale Sahul seraient arrivés il y a près de 40000 ans en provenance de l'asiatique Sunda. À cette époque, le niveau de la mer était d'environ quatre-vingt mètres plus bas et les distances entre les îles généralement plus courtes, les îles elles-mêmes bien mieux visibles dans le lointain. Comment, dans la pratique, s'est réalisée cette traversée de Sunda vers Sahul est bien difficile à décrire mais tout laisse croire que des radeaux très rudimentaires furent utilisés (Spriggs, 1997). La question s'est donc tout de suite posée de savoir si les cultures traditionnelles d'Océanie, qui sont des plantes à multiplication végétative, avaient été introduites sur Sahul sous la forme de fragments de tubercules, de cormes ou de boutures embarqués sur ces frêles embarcations en provenance de Sunda.

Nous venons de montrer que les apports de la biologie moléculaire indiquent clairement que ces plantes (arbre à pain, bananiers, canne à sucre, ignames, kava, taros) ont toutes une origine située à l'est de la ligne Wallace ${ }^{22}$, soit sur la plaque continentale Sahul elle même, soit sur les grandes îles mélanésiennes. En ce qui concerne l'aibika (Abelmoschus manihot) et le sagoutier (Metroxylon sagu), deux autres plantes très importantes, les données moléculaires disponibles confirment cette thèse (Lebot, 1999). Il est donc fort probable qu'il y a près de 40000 ans les premiers migrants étaient tout simplement démunis : sans céréales parce que leur domestication n'avaient pas encore eu lieu et sans les espèces dont ils allaient manipuler les formes sauvages trouvées dans les forêts tropicales au nord de Sahul pour en faire les cultures traditionnelles que nous connaissons aujourd'hui en Océanie. Pour ces espèces tout au moins le schéma semble désormais clair. Pour les grands arbres à noix ou à fruits tels que les Barringtonia, Canarium, Terminalia et autres, le schéma proposé semble s'en rapprocher et indique lui aussi une origine mélanésienne ou océanienne (Kirch, 1989).

Dans cette zone tropicale humide, très favorable à la croissance végétative, la domestication s'est faite par voie asexuée en capturant par clonage des formes spontanées jugées intéressantes. Des bananiers à fruits sans graines par exemple, des taros dont les faibles teneurs en cristaux d'oxalate de calcium les rendaient comestibles, des ignames dont les tubercules proches de la surface du sol, et non toxiques, étaient faciles à récolter et encore bien d'autres caractères utiles apparus au gré des recombinaisons. Une fois ces caractères capturés, la multiplication végétative a permis leur reproduction à l'identique et ces formes cultivées ont été transportées sur des pirogues à des milliers de kilomètres de leur aire d'origine.

\section{De rapides changements environnementaux}

Leur base génétique extrêmement étroite est désormais contraignante. Les agriculteurs ont répondu à cette étroitesse de l'agrobiodiversité en tentant de la diversifier. Cette diversification s'est faite, nous l'avons vu, en sélectionnant des mutants somatiques. Si certains caractères peuvent être très spectaculaires, comme un tubercule à chair pourpre par exemple, le nombre de gènes réellement impliqués dans leur contrôle est très faible, il s'agit parfois d'un seul gène responsable d'une coloration aérienne ou souterraine. La variabilité morphologique est grande mais la diversité génétique est faible.

Nunn (1990) a résumé les principaux changements d'origines climatique et anthropique que connaissent les pays du Pacifique. Ils se résument aux conséquences du réchauffement global, de la déforestation, des pressions anthropiques et de l'intensification des échanges inter insulaires. Ces changements environnementaux sont extrêmement rapides. Pour prendre un exemple concret : la population du Vanuatu va doubler ces vingt prochaines années du fait d'un taux d'accroissement démographique de $3 \% 1$ 'an et ce taux est de 3,4\% aux îles Salomon (SPC, 2000). Le développement d'une agriculture commerciale basée sur des plantes pérennes contribue également aux bouleversements des paysages en immobilisant durant de longues années des terres autrefois disponibles pour les rotations. Les flux migratoires, commerciaux et touristiques s'accélèrent et introduisent avec les hommes ou les marchandises un nombre croissant de prédateurs et de pathogènes.

Les populations de plantes dont la sexualité est active peuvent évoluer rapidement, surtout lorsqu'il s'agit d'espèces annuelles, en prenant l'avantage d'individus exceptionnels pour s'adapter. Les formes stériles, par contre, se trouvent dans un cul de sac évolutif et sont généti-

22. La ligne Wallace passe entre Bali et Lambok, longe l'ouest de Sulawesi puis s'insère entre Bornéo et les Philippines. Cette frontière biogéographique différencie les flores et faunes asiatiques et australiennes. La zone insulaire située entre Sunda et Sahul est dénommée Wallacea. 
quement vulnérables (Lebot, 1992). Les cultivars étant incapables de fructifier et de former des graines, ils n'ont pas accès aux recombinaisons génétiques pour répondre à ces changements environnementaux. En 1991, nous avions pris soin d'écrire que les cultivars de taro présents en Polynésie présentaient des zymotypes identiques aux variétés sensibles au Phytophthora colocasiae des îles Salomon et de Nouvelle-Guinée. Nous avions supposé (Lebot and Aradhya, 1991) que si ce pathogène était introduit en Polynésie, les cultures seraient décimées. En 1993, le $P$. colocasiae a fait son apparition à Samoa et en quelques mois les cultures furent réduites à néant. Une triste expérience qui rappelle l'introduction du Phytophthora infestans en Irlande au début du siècle lorsque la pomme de terre y était la plante alimentaire de base.

Les systèmes de culture traditionnels favorisent les associations entre espèces, ce qui reste malgré tout une forme de protection, mais le problème est que bon nombre de prédateurs et de pathogènes sont polyphages ${ }^{23}$. En ce qui concerne les principales maladies, la question de la source de l'inoculum est désormais préoccupante puisque certaines plantes cultivées représentent des foyers d'infestation potentiels. L'anthracnose par exemple (Colletotrichum gloeosporioides) est la principale maladie de la grande igname $(D$. alata) mais le manioc, bien que peu sensible, est un hôte de ce champignon. Si la relation de cause à effet n'a pas encore été démontrée, on assiste dans tous les pays du Pacifique à des épidémies de plus en plus virulentes d'anthracnose, tant et si bien qu'en NouvelleGuinée le D. alata tend à disparaître au profit du D. esculenta plus résistant. En Polynésie, ce sont les $D$. cayenensis et $D$. rotundata africaines qui remplacent la grande igname. Pour aggraver la situation, le rose beetle, ce coléoptère au vol maladroit, a été introduit au début des années 1980 et transforme en dentelle les feuilles de cette igname qu'il semble apprécier comme celle du bourao (Hibiscus tilliaceus) omniprésent, qui constitue une plante hôte et un mets de choix. Les exemples de ces polyphages sont nombreux, on trouve le charançon du bananier (Cosmopolitus sordidus) qui s'attaque aussi aux ignames ou encore les Papuana spp. qui consomment les cormes des taros et des autres aracées.

Pire encore est certainement le problème des viroses. Le virus de la mosaïque du concombre, par exemple, a été identifié comme étant l'agent causal principal du dépérissement du kava
(Davis 1996). On le trouve maintenant aussi sur des cultivars de $D$. alata et de nombreuses cultures, telles que la patate douce ou les bananiers, sont aussi des hôtes du CMV (cucumber mosaic virus). L'accumulation de particules virales est la principale cause de dégénérescence chez les plantes à multiplication végétative. Au fil des générations clonales, les rendements ne cessent de chuter pour atteindre des niveaux qui obligent les agriculteurs à abandonner certaines plantes pour en choisir d'autres. L'introduction dans le Pacifique de plantes à racines et tubercules d'origine américaine (manioc, patate douce et macabo), et leur spectaculaire succès, sont dus à la régression des performances des cultures traditionnelles et aux forts rendements des espèces exotiques. Les agriculteurs les multiplient très rapidement, parfois exagérément, en oubliant qu'elles peuvent aussi être vulnérables. La récente famine sur les hautes terres de NouvelleGuinée était en partie due à des systèmes de cultures à dominantes de patate douce (Ipomoea batatas) et de macabo (Xanthosoma sagittifolium) dont les clones n'ont pas résisté à la sécheresse exceptionnellement longue causée par le phénomène El Niño en 1997 (Bourke et al., 2001).

\section{Les enjeux pour la recherche et le développement}

Compte tenu des contraintes énoncées précédemment, il est fort probable qu'à l'avenir, les agriculteurs vont rencontrer des problèmes grandissants avec ces cultures traditionnelles d'Océanie. La situation est d'autant plus préoccupante que, pour la plupart, ces cultures sont dites " orphelines » du système de recherche agronomique international. Elles ne font pas partie du mandat des grands instituts ${ }^{24}$ et sont donc négligées par les bonnes intentions occidentales qui se concentrent sur les principales plantes alimentaires, surtout des céréales. Dans le Pacifique, la recherche agronomique rencontre les difficultés que connaissent les pays en voie de développement en général et qui relèvent de l'absence de moyens et de chercheurs nationaux.

Il devient important pour les agriculteurs de disposer de bonnes plantes. L'amélioration variétale est certainement l'approche la plus durable sur le long terme. Elle est respectueuse de l'environnement puisqu'elle permet d'éviter le recours aux pesticides, mais la complexité de la situation nécessite une approche internationale.

23. Se dit d'un organisme capable de se nourrir de diverses espèces ou de les parasiter.

24. Le système CGIAR (Consultative Group for International Agricultural Research) financé essentiellement par la Banque mondiale, rassemble des instituts de recherche spécialisés et distribués géographiquement. 
Il convient pour pouvoir améliorer de conserver ce qui existe, c'est-à-dire de protéger les ressources génétiques. Mais conserver est problématique pour ces plantes dont les graines sont dites récalcitrantes ${ }^{25}$. Par ailleurs, on observe que la conservation n'a de sens que si les variétés locales sont utilisées, ce qui suppose qu'il existe des programmes d'amélioration, et ils sont rares aujourd'hui. Leur conservation à la ferme, chez l'agriculteur, suppose quant à elle que ce dernier se préoccupe réellement de l'avenir de ces plantes et de leur biodiversité. C'est possible, mais on observe aussi que l'actuelle érosion culturelle des hommes est aussi la cause principale de l'érosion génétique des plantes.

L'amélioration génétique de ces espèces nécessite que l'on croise les meilleurs cultivars locaux avec des génotypes distants dans le but de capturer de la vigueur hybride. Le judicieux choix des parents implique qu'on ait une idée de la diversité génétique existante. C'est en partie fait et nous venons de l'expliquer, mais il faut aussi que l'on puisse disposer de sources de gènes exotiques. Puisque bon nombre de maladies viennent d'ailleurs, les gènes de résistance sont donc à rechercher ailleurs que dans le Pacifique lui même. En ce qui concerne l'amélioration génétique du taro par exemple, il convient de pouvoir bénéficier de géniteurs asiatiques pour améliorer la résistance des cultivars locaux au $P$. colocasiae. Cet exercice est difficile à réaliser dans la pratique. Les environnements insulaires sont si fragiles que toute introduction de matériel végétal étranger nécessite le passage obligatoire par un centre de transit situé en dehors de cette zone géographique. Par centre de transit, on entend une procédure de quarantaine ex situ nécessaire pour effectuer l'indexation virale ${ }^{26}$ et la mise en culture in vitro, une condition désormais requise pour la distribution de matériel végétal. Les pays insulaires ont tellement souffert des introductions anarchiques de pathogènes que leurs services de protection phytosanitaire sont de plus en plus stricts. Aujourd'hui, des mesures drastiques existent et sont appliquées.

Le problème est que la situation est extrêmement complexe d'un point de vue scientifique. Nous avons vu que l'origine de ces cultivars résulte souvent de l'agrégation de plusieurs génomes différents, les génotypes sont donc fortement hétérozygotes. Cette hétérogénéité se traduit par une très forte variabilité des caractères dans les hybrides où se fait l'essentiel de la sélection variétale. En raison du peu de travaux d'amélioration conduits, ou de leur jeunesse, de nombreux caractères sauvages délétères réapparaissent dans les descendances et la proportion d'individus indésirables est souvent très importante. Cette contrainte oblige les améliorateurs à cribler un très grand nombre de descendants pour augmenter leurs chances de sélectionner peu d'individus exceptionnels.

Dans la plupart des cas cependant, il reste encore difficile, même pour les chercheurs, d'obtenir ces hybrides en raison des diverses causes de stérilité. L'amélioration génétique du kava ou des ignames par exemple, est encore à l'état de projet scientifique. On ne sait toujours pas mettre in vitro le $P$. methysticum, condition nécessaire à l'assainissement des plants infectés par le CMV. Pour le kava comme pour les ignames, on ne sait toujours pas induire les floraisons pour faciliter les croisements. Contrairement aux céréales qui ont été améliorées de manière empirique, mais efficace, par les agriculteurs euxmêmes durant des millénaires, les plantes à multiplication végétative ne peuvent être améliorées que par des équipes de chercheurs disposant de solides connaissances et des moyens conséquents. On le voit, il s'agit d'opérations lourdes et fastidieuses. La recherche sur ces plantes devrait donc travailler en réseaux en associant des compétences diverses et complémentaires. Elle balbutie encore.

On le sait, la dépendance alimentaire du Pacifique est inquiétante. Au Vanuatu par exemple, la valeur des denrées alimentaires importées dépasse tous les ans la valeur des exportations agricoles. L'amélioration de la faible productivité des agricultures locales passera forcément par l'amélioration génétique de leurs plantes. Il est donc probable que la région va prendre conscience des efforts qui seront nécessaires pour les améliorer. Si ces efforts venaient à tarder, ces plantes perdraient la place dominante qu'elles ont occupée dans les systèmes de culture. $\mathrm{Ce}$ processus a déjà commencé, s'il devait s'accélérer, les changements de régimes alimentaires pourraient avoir de sérieuses conséquences sur la santé des populations et des économies insulaires. Barrau (1955) notait déjà qu'une alimentation composée de manioc cultivé localement et de riz blanc importé n'était guère salubre. Bon

25. Les graines récalcitrantes ne se prêtent pas à la conservation de longue durée au froid et perdent leur pouvoir germinatif rapidement.

26. Puisqu'il est hors de question d'introduire des virus avec le matériel végétal, il convient de les détecter puis d'assainir le matériel avant de le distribuer. 
nombre de ses observations sont plus que jamais d'actualité.

\section{BIBLIOGRAPHIE}

Argent H., 1976. The wild bananas of Papua New Guinea. Bulletin of the Royal Botanical Gardens, Edinburgh 30 : 77-114.

BARRAU J., 1955. L'Agriculture vivrière mélanésienne. Commission du Pacifique Sud. Nouméa, Nouvelle Calédonie.

—, 1962. Les plantes alimentaires de l'Océanie : origines, distribution et usages. Thèse de Doctorat, Faculté des Sciences de Marseille.

Bellwood P., 1985. Prehistory of Indo-Malaysian Archipelago. Sydney Academic Press.

Bourke R.M., M.G. Allen and J.G. Salisbury (eds.), 2001. Food Security for Papua New Guinea. Proceedings of the Papua New Guinea Food and Nutrition 2000 Conference, PNG, University of Technology, Lae, 26-30 June 2000. ACIAR Proceedings no. 99, XVIII $+892 \mathrm{p}$.

BLust R., 1985. The Austronesian homeland : A linguistic perspective. Asian Perspectives 26 : 45-67.

CARreel F., 1994. Étude de la diversité génétique des bananiers (genre Musa) à l'aide de marqueurs RFLP. Thèse de Doctorat, I.N.A. Paris Grignon.

Coursey D.G., 1976. Yams. In N.W. Simmonds (ed), Evolution of crops plants, London.

Daniels J. and B.T. RonCH, 1987. Taxonomy and evolution. Chapter 2. In D.J. Heinz (ed.), Sugarcane improvement through breeding. Elsevier Press, Amsterdam, pp. 7-84.

Davis R.I., 1996. Causal relationship between cucumber mosaic cucmovirus and kava dieback in the South Pacific. Plant Disease 80 (2) : 194-197.

Degras L., 1986. L'igname, Plante à tubercule tropicale. Maisonneuve et Larose, Paris, 408 p.

Glaszmann J.C., J.L. Noyer, A. Fautret, P. FeldMANN, et C. LANAUD, 1989. Biochemical genetic markers in sugarcane. Theor. Appl. Genet. 78: 537543.

Hahn S.K., 1987. Yams, Dioscorea spp. (Dioscoreaceae). In N.W. Simmonds (ed.), Evolution of Crops Plants. London, pp. 112-120.

Ivancic A. and Lebot V., 1999. Botany and Genetics of New Caledonia Wild Taro (Colocasia esculenta (L.) Schott). Pacific Science 53 (3): 273-285.

Jacquot M., G. Clément, A. Ghesquière, J.C. Glaszmann, E. Guiderdoni et D. Tharreau, 1997. Les riz. In Charrier, Jacquot, Hamon, Nicolas (eds), L'amélioration des Plantes Tropicales. Collection « Repères » CIRAD ORSTOM, France, 623 p.

KIRCH P.V., 1989. Second millennium BC arboriculture in Melanesia: Archeological evidence from the Mussau Islands. Economic Botany 43 : 224-240.
—, 1997. The Lapita peoples : ancestors of the oceanic world. The Peoples of South-East Asia and the Pacific. Blackwell Publishers, Cambridge Massachusetts, $353 \mathrm{p}$.

Krieke N., H. Van Eck, V. Lebot, submitted. Genetic diversity in taro (Colocasia esculenta) from South East Asia and Oceania. Soumis à Theor. Appl. Genet.

Lевот V., 1992. Genetic vulnerability of Oceania's traditional crops. Experimental Agriculture 28 (3) : 309-323.

—, 1999. Biomolecular Evidence for Crop Domestication on Sahul. Genetic Resources and Crop Evolution 46: 619-628.

LeBot V. and J. LÉVESQue, 1989. The origin and distribution of kava (Piper methysticum Forst. f., Piperaceae) : a phytochemical approach. Allertonia 5 (2) : 223-380, National Tropical Botanical Garden, Hawaii.

Lebot V. and M. Arhadya, 1991. Isozyme Polymorphism in Taro (Colocasia esculenta Schott.). Euphytica (56) : 55-66.

Lebot V., M. Arhadya and R. M. Manshardt, 1991. Geographical survey of genetic variation in kava (Piper methysticum). Pacific Science 45 (2) : 169185.

Lebot V., M. Merlin and L. Lindstrom, 1992. Kava : the Pacific Drug. Yale University Press, Psychoactive Plants of the World series, $260 \mathrm{pp}$.

Lebot V., M. Arhadya, R. M. Manshardt and B. MeILleur, 1993. Genetic relationships among cultivated bananas and plantains from Asia and the Pacific. Euphytica (67) : 163-175.

Lebot V., V. Trilles, J.L. Noyer and J. Modesto, 1998. Genetic relationships between yam (Dioscorea alata) cultivars. Genetic Resources and Crop Evolution 45 : 499-509.

Lebot V., E. Johnston, Q.Y. Zheng, D. McKern and D. McKenna, 1999. Morphological, Phytochemical and Genetic Variation in Hawaiian Cultivars of 'Awa (Kava, Piper methysticum, Piperaceae). Economic Botany 53 (4) : 407-418.

Lu Y.H., A. D'Hont, D.I.T. Walker, P.S. Rao, P. Feldmann and J.C. Glaszmann, 1994. Relationships among ancestral species of sugarcanes revelaed with RFLP using single copy maize nuclear probes. Euphytica $78: 7-18$.

Malapa R., 2000. Étude de la diversité génétique des cultivars de $D$. alata $\mathrm{L}$. du Vanuatu par les marqueurs morpho-agronomiques et AFLP. DEA de génétique, adaptation et production végétales. Université de Rennes I, ENSA de Rennes.

Martin F.W. and A.M. RHodes, 1977. Intra-specific classification of Dioscorea alata. Tropical Agriculture (Trinidad) $54: 1-13$.

Matthews P.J., 1990. The origins, dispersal and domestication of taro. $\mathrm{PhD}$ thesis, Australian National University, Canberra, Australie. 
NuNN P.D., 1990. Recent environmental changes on Pacific Islands. The Geographical Journal, The Royal Geographical Society 156 : 124-140.

Plucknett D.L., 1976. Edible Aroids : Alocasia, Colocasia, Cyrtosperma, Xanthosoma. In N.W. Simmonds (ed), Evolution of Crop Plants 10-12, London, Longman.

RAGONE D., 1991. Variability of breadfruit in the Pacific Islands. PhD Dissertation, Department of Horticulture, University of Hawaii, Honolulu.

—, 1997. Breadfruit, Artocarpus altilis (Parkinson) Fosberg. Promoting the conservation and use of underutilized and neglected crops. 10. Institute of Plant Genetics and Crop Plant Research, Gatersleben/International Plant Genetic Resources Institute, Rome, Italy.

Ramser, J., C. López-Peralta, R. Wetzel, K. WeiZING and G. KAHL, 1996. Genomic variation and relationships in aerial yam (Dioscorea bulbifera L.) detected by random amplified polymorphic DNA. Genome 39 : 17-25.

Secretariat of the Pacific Community (sPC), 2000. Oceania Population 2000. Demography/Population Programme, Nouméa, Nouvelle Calédonie.

Sharrock S., 1995. Collecting the Musa gene pool in Papua New Guinea. Chap. 33, pp. 647-658. In Guarino et al (eds) Collecting Plant Genetic Diversity, the technical guidelines. IPGRI, Rome, CAB International.

SimÉONi P., 1998. Profession « kavaculteur » : nouveau bâtisseur de la ruralité vanuataise. In le Voyage inachevé... à Joël Bonnemaison. Paris, Éditions de l'ORSTOM/PRODIG, pp.463-469.
Spriggs M., 1997. The Island Melanesians. The Peoples of South-East Asia and the Pacific. Blackwell Publishers, Cambridge Massachusetts. 326 pages.

Stover R.H. and N.W. Simmonds, 1987. Bananas. In N.W. Simmonds (ed.), Evolution of Crops Plants, London, pp. 370-375.

Terauchi R.T., T. Terachi and K. Tsunewaki, 1991. Intraspecific variation of chloroplast DNA in Dioscorea bulbifera L. Theor. Appl. Genet. 81 : 461470.

Wood B., 1988. Characterization of the world collection of sugarcanes and related grasses by isozyme analysis. Final Report, USDA/ARS, Subtropical Horticultural Research Station, Miami, Florida.

YeN D.E., 1991a. Polynesian cultigens and cultivars : the question of origin. In P.A. Cox and S.A. Bannack (eds) Islands, Plants and Polynesians, Dioscorides Press, Portland, Oregon, pp. 67-95.

—, 1991b. Domestication : the lessons from New Guinea. In A. Pawley (ed), Man and a half : essays in honour of Ralph Bulmer, Polynesian Society, Auckland, pp. 558-569.

-, 1993. The Origins of Subsistence Agriculture in Oceania and the Potential for Future Tropical Food Crops. Economic Botany, 47 (1) : 3-14.

Zerega N.C., D. Ragone, T.J. Motley, L.B. Garden and D. Cullman, 2001. Hybrid Origin of Breadfruit (Artocarpus altilis). Communication présentée au International Summit on Issues Involving Indigenous peoples, Conservation, Sustainable Development and Ethnoscience May 28-June 2, 2001. Honolulu, Hawaii. 